\title{
LONG SERIES OF GNSS INTEGRATED PRECIPITABLE WATER AS A CLIMATE CHANGE INDICATOR
}

\author{
Michał Kruczyk \\ Department of Geodesy and Geodetic Astronomy, \\ Faculty of Geodesy and Cartography, Warsaw University of Technology \\ Warsaw, Poland
}

\begin{abstract}
This paper investigates information potential contained in tropospheric delay product for selected International GNSS Service (IGS) stations in climatologic research. Long time series of daily averaged Integrated Precipitable Water (IPW) can serve as climate indicator. The seasonal model of IPW change has been adjusted to the multi-year series (by the least square method). Author applied two modes: sinusoidal and composite (two or more oscillations). Even simple sinusoidal seasonal model (of daily IPW values series) clearly represents diversity of world climates. Residuals in periods from 10 up to 17 years are searched for some long-term IPW trend - self-evident climate change indicator. Results are ambiguous: for some stations or periods IPW trends are quite clear, the following years (or the other station) not visible. Method of fitting linear trend to IPW series does not influence considerably the value of linear trend. The results are mostly influenced by series length, completeness and data (e.g. meteorological) quality. The longer and more homogenous IPW series, the better chance to estimate the magnitude of climatologic IPW changes.
\end{abstract}

Keywords: water vapour, GPS, IPW, IWV, tropospheric delay, climate change, climatological time series

\section{Introduction}

Atmospheric refraction of Global Positioning System (GPS) L-band navigational signal is named as tropospheric delay of pseudorange. For GPS measurement taken for satellite at zenith and a receiver located at sea level, the zenith tropospheric delay (ZTD), in units of length, amounts to approximately $2.3 \mathrm{~m}$. The ZTDs need to be properly handled if high accuracy (several millimeters) of station coordinates is needed. Due to limited accuracy of existing ZTD models, the most precise applications of GPS (geodynamics, geodetic reference frames), require the 
estimation of ZTDs during the adjustment of GPS observations, together with other parameters, e.g., station coordinates, phase ambiguities. Because of temporal variability, ZTDs are usually estimated every one hour for each station (24 parameters for daily session). So we eliminate tropospheric delay in GPS solutions by the proper construction and solution of observational equation system so as tropospheric delay is estimated stochastically together with coordinates (HoffmanWellenhof B., 2008; chapter 5.3). In case of permanent GPS stations (maintained for most precise scientific solutions) the GPS derived ZTDs are also used for the purposes of atmospheric research and are the basis for GPS meteorology (Duan et al., 1996). ZTD is a sum of zenith wet delay (ZWD) and zenith hydrostatic delay (ZHD). Zenith wet delay, which is about $10 \%$ of ZTD, depends mostly on the content of water vapor along the path of signal propagation and is highly variable both spatially and temporally. ZHD depends mostly on surface atmospheric pressure, and can be computed at the several millimeter accuracy level from existing ZHD models using surface meteorological data (in our work Saastamoinen formula with gravitational correction is function of surface atmospheric pressure).

A number of studies have shown that IPW estimates from ground-based GPS observations and meteorological/aerologic data give the same level of accuracy as aerologic techniques.

Water vapor is extremely important (even if relatively small) part of water cycle and plays crucial role in many meteorological, climatologic and environmental processes (such as evapotranspiration, condensation, precipitation, thermodynamics - latent heat release, cloudiness and its impact on insolation etc.) as acknowledged in numerous sources (even at the textbook level - e.g.: Shelton, 2009, Andrews, 2010, Mcllven, 2010, Salby, 2012). Water vapor is a greenhouse gas even more important than carbon dioxide (but of course lasts in the atmosphere for a short time). Of 30 Celsius degrees greenhouse effect observed on Earth, water vapor if responsible for nearly $21^{\circ}$ whereas $\mathrm{CO}_{2}$ slightly above $7^{\circ}$. In warmer atmosphere saturation water vapor pressure is higher (exponential increase with temperature) and likewise water vapor density at the same relative humidity level. It is predicted that an increase in temperature of $1^{\circ} \mathrm{C}$ will increase the water vapor content by 6-7\% (Trenberth et al., 2003). So water vapor is both climate change agent (generates global warming effect) and indicator (signals rising average temperatures). Water vapor - the primary greenhouse gas enhance the atmospheric greenhouse effect temperature rise in a cycle of positive feedback by rising ocean temperatures and an increase in evaporation rates. At the same time after condensation in the form of clouds water vapor provides negative radiative forcing (Forster et. al., 2007). The idea to use IPW derived from GPS solutions as a climate change indicator probably first appeared in 1993 (Yuan et. al., 1993). Several other studies already aimed to obtain long-term trends in IPW (or ZWD) using both GNSS and VLBI data (Gradinarsky et al., 2002, Jin et. al., 2007, Ning and Elgered, 2012). Climate change can be studied also by means of ZTD series analysis (e.g.: Bałdysz et al., 2015).

\section{IGS tropospheric product and IPW derivation}

There are several tropospheric solutions to find as part of the IGS products available in Data Centers repositories. IGS solutions are divided into three periods:

- combined product (till mid 2006), by Gerd Gend, weighted mean of IGS Analysis Centers solution plus statistics; 
- new IGS tropospheric product (2002-2011), by Sung. H. Byun \& Yoaz. E. BarSever, JPL, Gipsy-Oasis, solution utilizes final IGS GPS orbit and clock solutions (see: Byun, Bar-Sever, 2009);

- IGS tropospheric product (from 2011) by Sharyl Byram, USNO, Bernese GPS Software Version 5.0.

EPN (EUREF) provides combined product (by W. Soehne/ R. Pacione), IGS Analysis Centers individual solutions: CODE, SIO, NGS, JPL, EMR and EPN Analysis Centers solutions. The problems with GPS strategy and reference system changes can be solved by reprocessing, the impact of EPN reprocessing on long "climatologic" IPW changes has been already examined (Kruczyk, Liwosz, 2012).

IPW (Integrated Precipitable Water) sometimes denoted simply as PW is an interesting meteorological parameter describing quantity of water vapor in the vertical direction over station in $\mathrm{mm}$ of liquid water after condensation. Related parameter IWV (Integrated Water Vapor) is also used which has the same numerical value but another unit of measure: $\mathrm{kg} / \mathrm{m}^{2}$. IPW can be calculated from ZTD by known procedure of separating ZHD (Zenith Hydrostatic Delay) and recalculating obtained ZWD (Zenith Wet Delay) by numerical coefficient dependent on so called 'mean temperature' in vertical profile of atmosphere. For ZWD separation we need direct measurements of meteorological parameters at GNSS station. But the points equipped with them are quite sparse. From numerical weather prediction models we get meteorological data and consequently IPW for every station inside model grid. Also meteorological parameters for every GNSS station can be obtained by geostatistical fitting of measurements at points of meteorological network (SYNOP or METAR). But in case of climatological series when we need highest accuracy such approach (especially in case of atmospheric pressure) seems not appropriate.

Integrated precipitable water (IPW) i.e. total column of water vapor (as liquid) is derived from ZTD solution by widely known procedure involving first the separation of Wet Delay by calculation of Hydrostatic Delay:

$$
Z W D=Z T D-Z H D
$$

To calculate ZHD in this work Saastamoinen formula has been used:

$$
Z H D=(2.2779) p / f(\varphi, H)
$$

Where $f$ function reproduces changes of the force of gravity with latitude $\varphi$ and ellipsoidal height $\mathrm{H}$ in kilometers (Davis et al. 1985):

$$
f(\varphi, H)=(1-0.00266 \cos 2 \varphi-0.00028 H)
$$

Next we recalculate obtained ZWD by coefficient $\mathrm{k}$ dependent on so called 'mean temperature' in vertical profile of atmosphere (Bevis et al. 1992, Rocken et al. 1993).

$$
I P W \approx \frac{\kappa}{\rho_{l w}} \cdot Z W D
$$


Coefficient $\kappa$ is given by equation:

$$
1 / \kappa=10^{-6}\left(C_{3} / T_{m}+C_{2}^{\prime}\right) R_{w v}
$$

and has value of about $1 / 6.4\left\{R_{v}=R / M_{w v}\right.$ is specific gas constant for water vapor, $T_{m}$ - 'mean temperature', $C_{x}$ are empirical coefficients given in many versions by different sources and $\rho_{l w}$ liquid water density\}. Coefficient $K$ depends on temperature profile but can be estimated by means of surface temperature at the GNSS station (Bevis et al. 1992):

Coefficient $k$ depends on temperature profile but can be estimated by means of surface temperature $\left(T_{s}\right)$ at the GNSS station:

$$
T_{m} \approx 70.2+0.72 \cdot T_{s}[\mathrm{~K}]
$$

This average formula for mean temperature obtained from 8718 radiosunding profiles in the US for latitudes: $27^{\circ}-65^{\circ} \mathrm{N}$ is enough for this work. Author main aim here is to analyse IPW series for each station separately and without other technique inclusions.

Here are other details of the process to prepare data:

1) ZTD estimates of 5 minute interval are averaged in hourly intervals;

2) Meteorological data of different time step (discretion of IGS station operator) are averaged in hourly intervals (2-hour intervals for old IGS tropospheric combination);

3) Hourly (or bi-hourly) data are subject of IPW calculation as described above

4) IPW and other data are once more averaged in daily intervals;

5) Yearly files are merged in multi-year series (by consecutive day number from the beginning of the first year in the series).

33 IGS stations have been processed in this vein. Main criteria to include a station were at least 10 - year consecutive series of both ZTD (IGS combination - till 2005 and IGS "new" product from 2006) and local meteorological measurements (station meteo Rinex at IGS Data Centers). Author used only stations equipped with meteorological sensors. Meteorological data required for IPW calculation in this work were not collocated from outside sources (meteorological services, numerical weather model or standard atmosphere).

\section{Climate information in IPW from IGS tropospheric product}

This work examines only IGS tropospheric delay product but in relatively long series. The author already examined IPW data from IGS tropospheric product as a source of data related to climate characteristic (Kruczyk, 2014).

Let us first look at such a long series of daily IPW averages and note considerable similarity to daily averages of temperature (Fig. 1 and 2). The only significant IPWtemperature divergence are the extremes: for IPW - positive, in case of temperature negative. The peak values happen in the height of summer (IPW) or winter (temperature). Long lasting changes in weather conditions - 'dry' and 'wet' years are visible (see also model of annual oscillation on Fig. 9). 


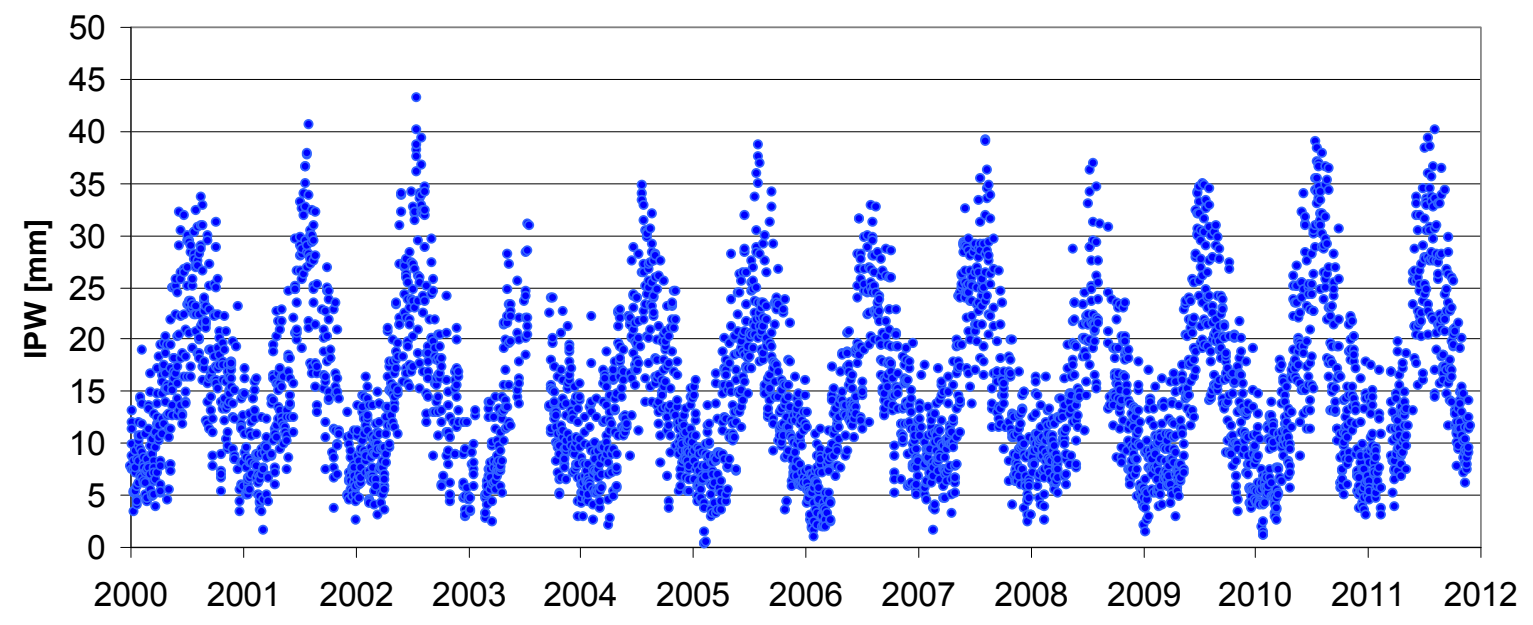

Fig. 1. Daily IPW for JOZE during 12 years (IGS tropospheric product)

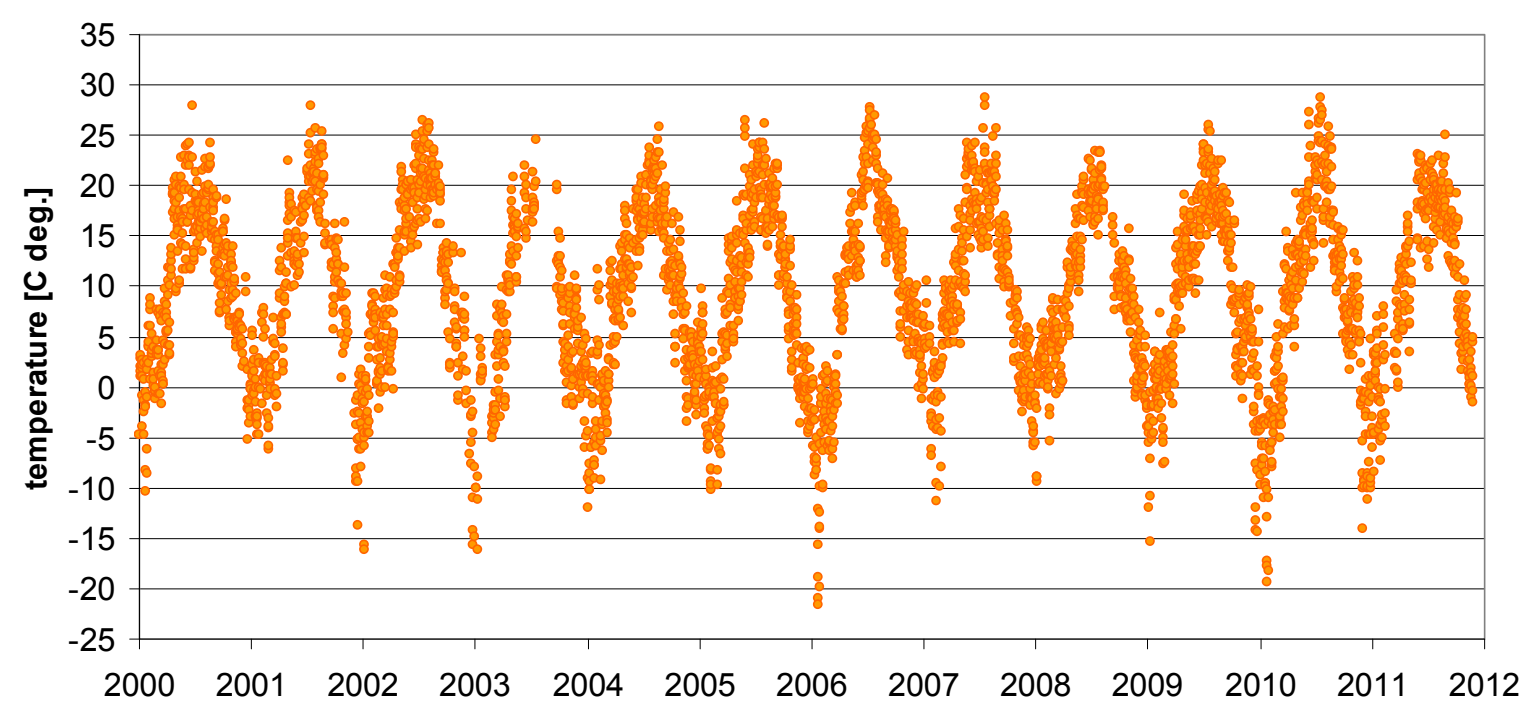

Fig. 2. Daily temperature averages at JOZE during 12 years (local sensor)

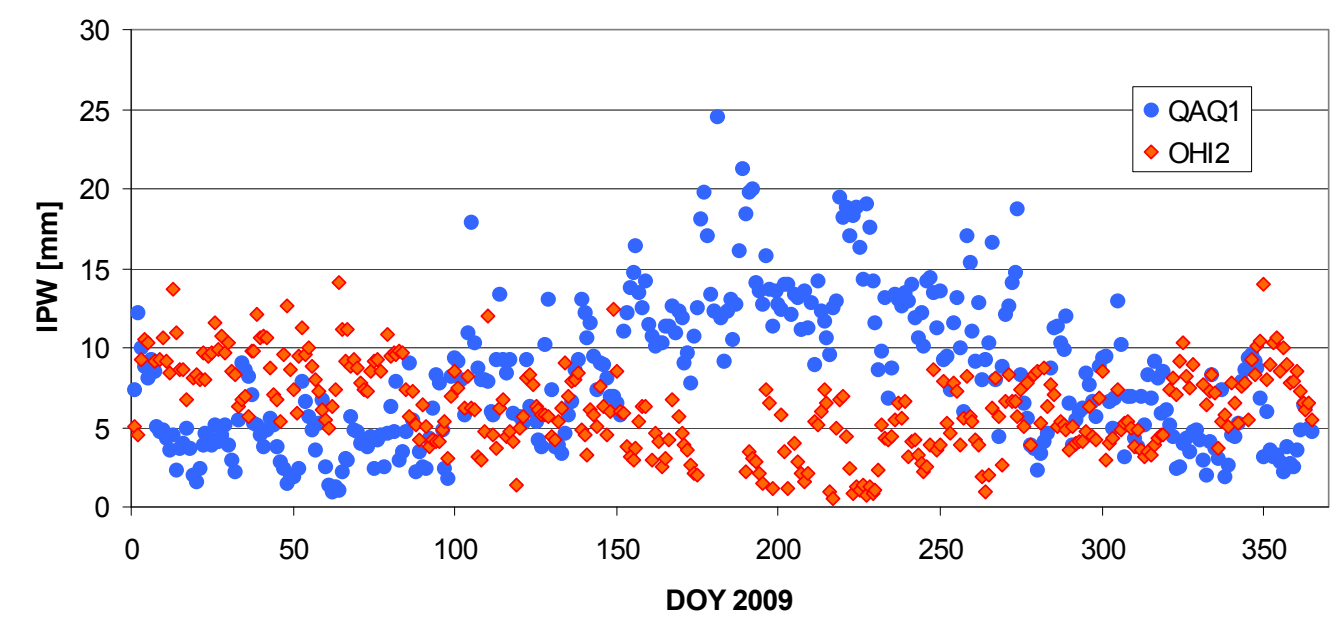

Fig. 3. Daily mean IPW in 2009 for QAQ1 (South Greenland) and OHI2 (Antarctic Peninsula), IGS tropospheric product 
Daily averaged IPW values obviously carry some climatological information. Below You can see the series for GPS station pairs in different climates: QAQ1 - South Greenland and $\mathrm{OHI} 2$ - Antarctica (Fig.3).

Simple model (sinusoid - amplitude and phase plus constant) has been adjusted to the series (by the least square method) for selected stations. First I adjust every year separately - we get different not only amplitudes but also phases. IPW amplitudes are a clear indicator of seasonal extremes. In case of stations at the same latitude IPW seasonal amplitude indicates climate continentality. The moment when IPW reaches the maximum also depends on station distance from the ocean. Figures $4-$ 6 show the sinusoidal IPW model for some IGS/EPN stations. Note northern and southern hemisphere stations distinctive behavior; also growth of the seasonal amplitudes (with latitude change) is visible. Set of IGS stations of course shows much bigger discrepancy. We can easily distinguish northern and southern hemisphere.

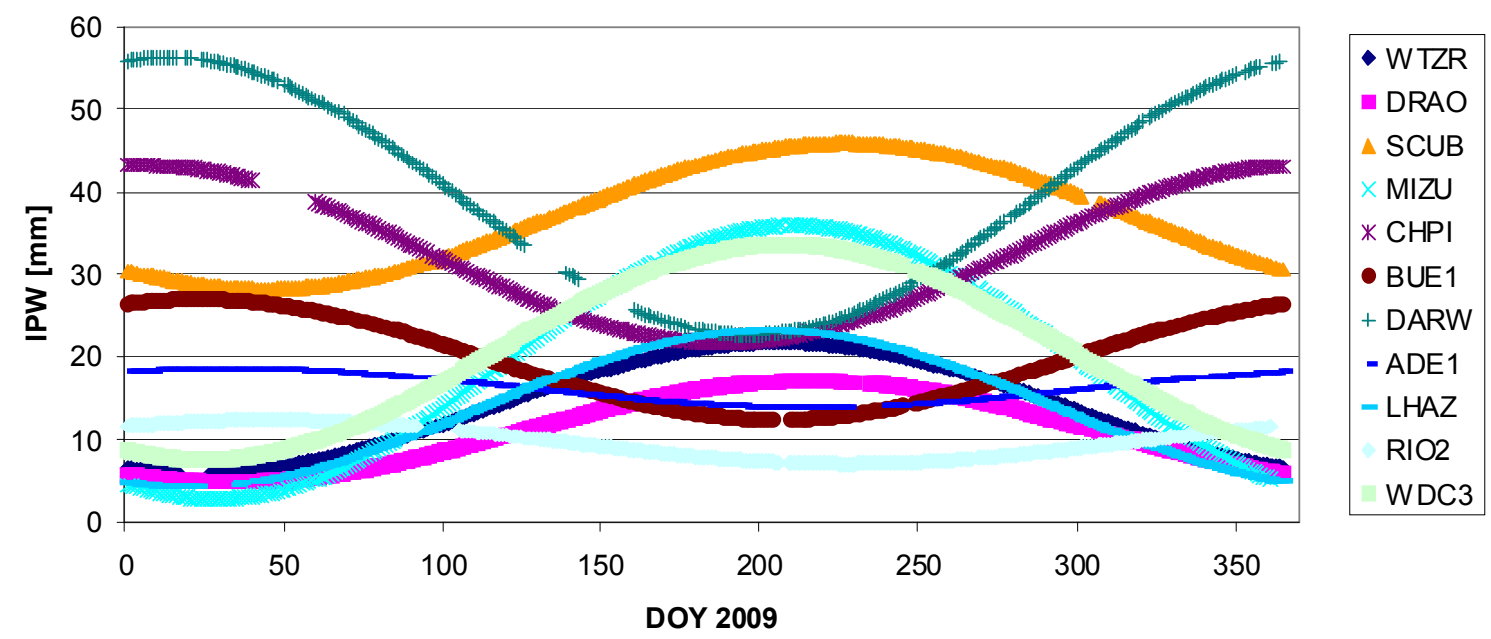

Fig. 4. Integrated precipitable water annual model for selected IGS stations in 2009 (CODE global solution)

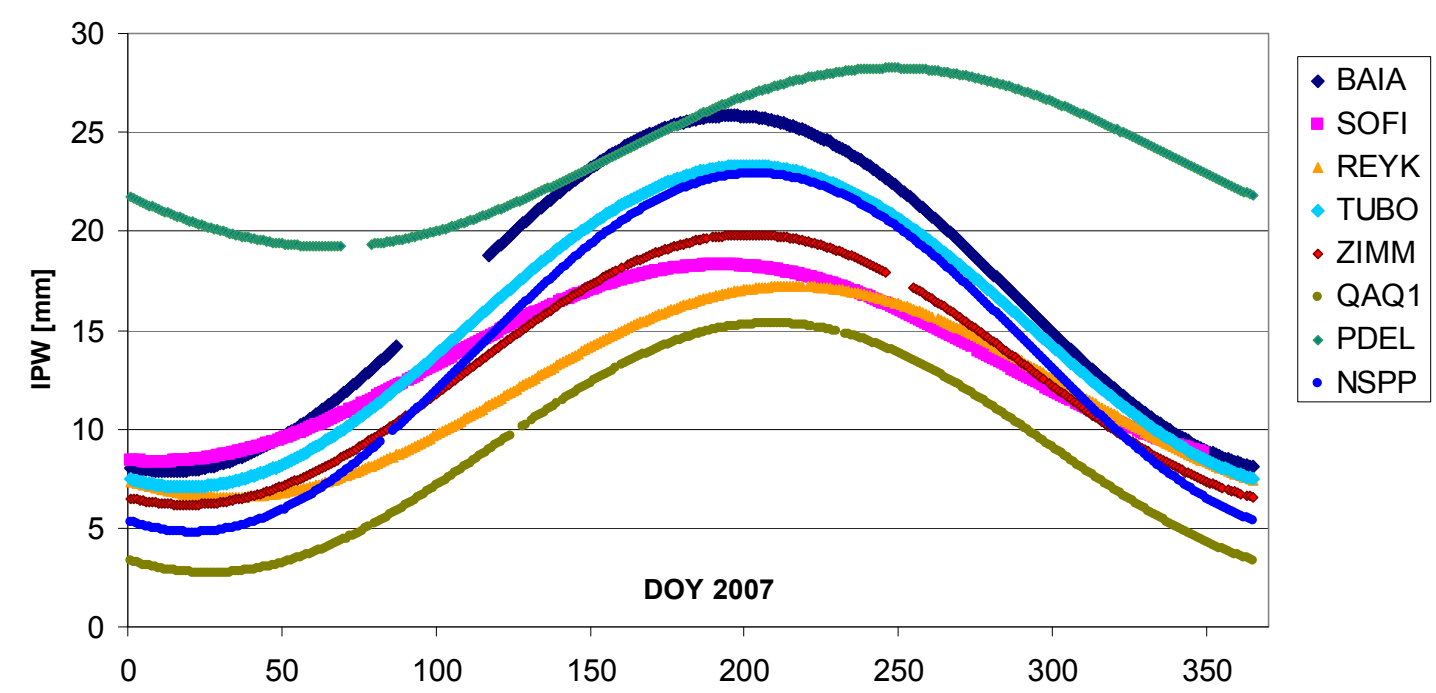

Fig. 5. Integrated precipitable water annual model for selected EPN stations in 2007 (EPN combined tropospheric product) 


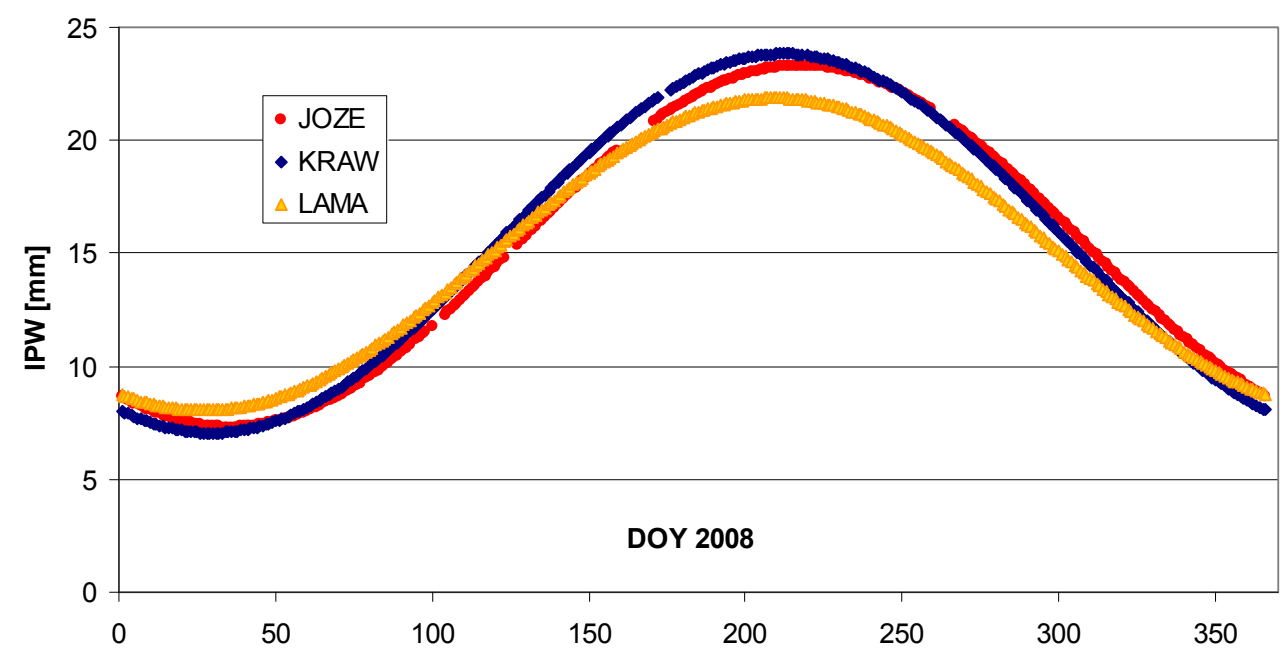

Fig. 8. Integrated precipitable water annual model for 3 EPN stations in Poland (EPN combined tropospheric product) 2008

\section{In search of climate change signal in IPW long series}

At first let us apply our simple model (sinusoid - amplitude and phase plus constant) adjusted to the series divided into separate years for e.g. JOZE. Only multi-year adjustment has climatologic value but to adjust every year separately gives clue of inter-annual variability: different are not only amplitudes but also phases.

Can we hope to find something of global change? First let us will apply out model for multi-year series of IPW from IGS ZTD solutions in search for some climate change signal in residuals.

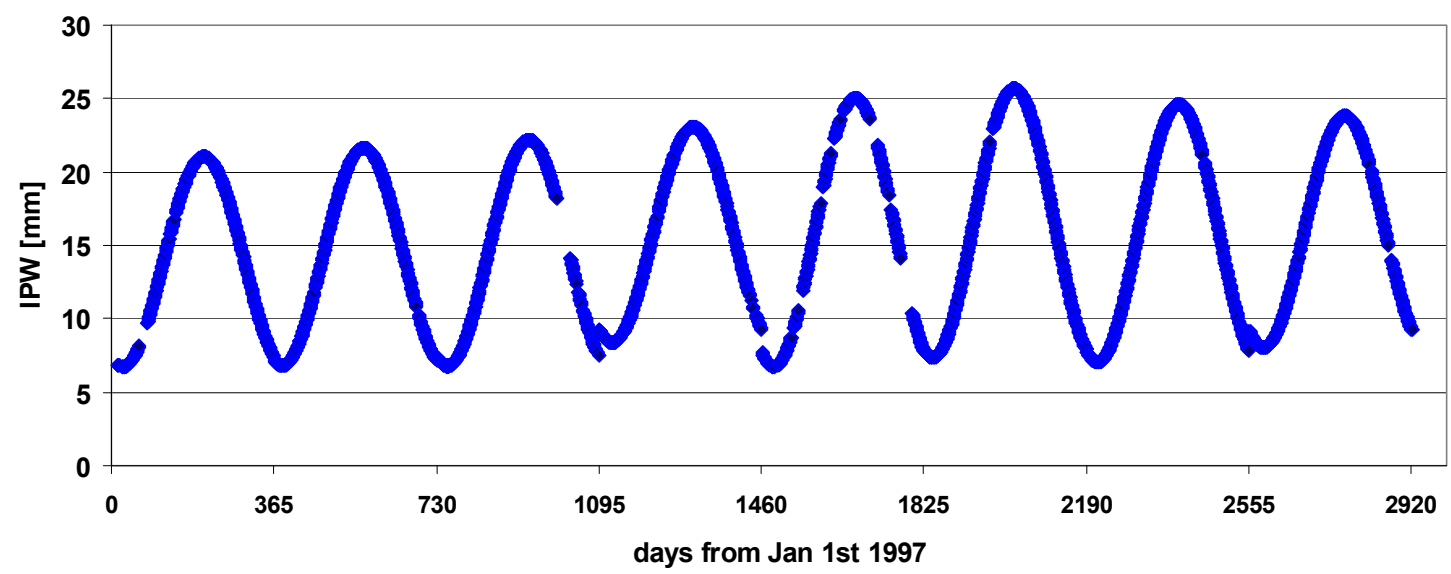

Fig. 9. Results for 8 years (1997-2004) for JOZE from IGS CODE global solution, during first 5 years period there is $+0.6 \mathrm{~mm} /$ year IPW trend. For the following years not visible. Each year is fitted separately - so the jumps at the year beginning. 


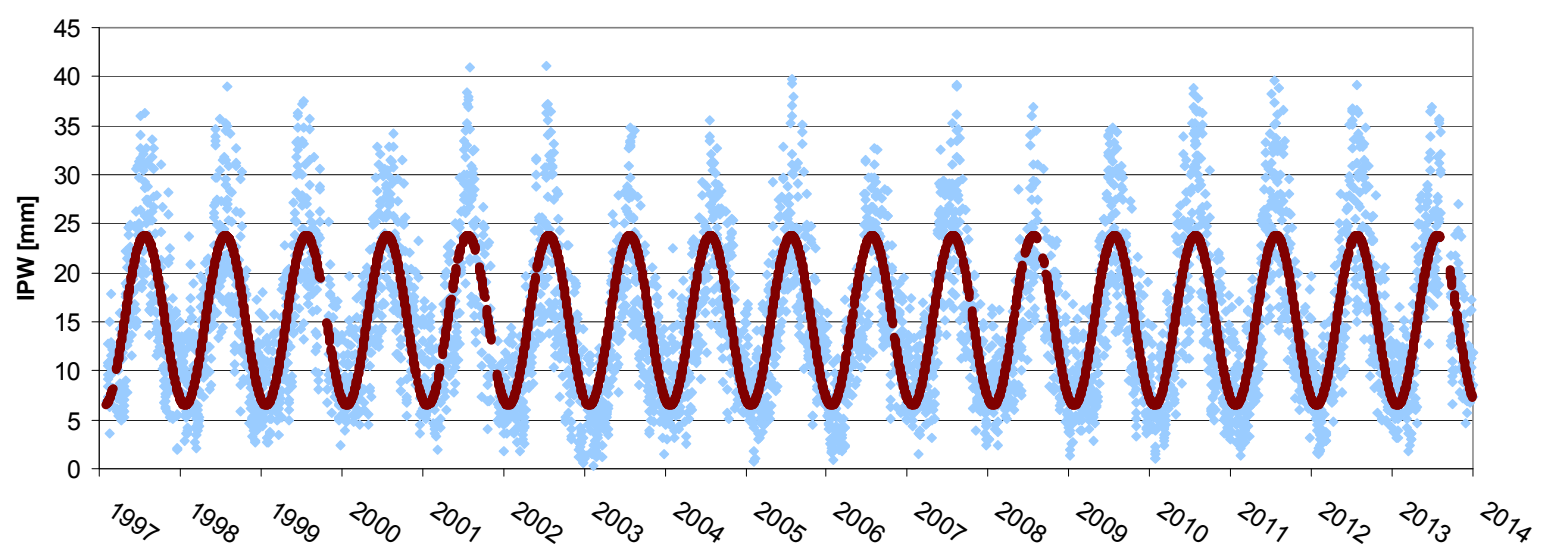

Fig. 10. IPW for JOZE and simple annual oscillation model applied to 1997-2013 period

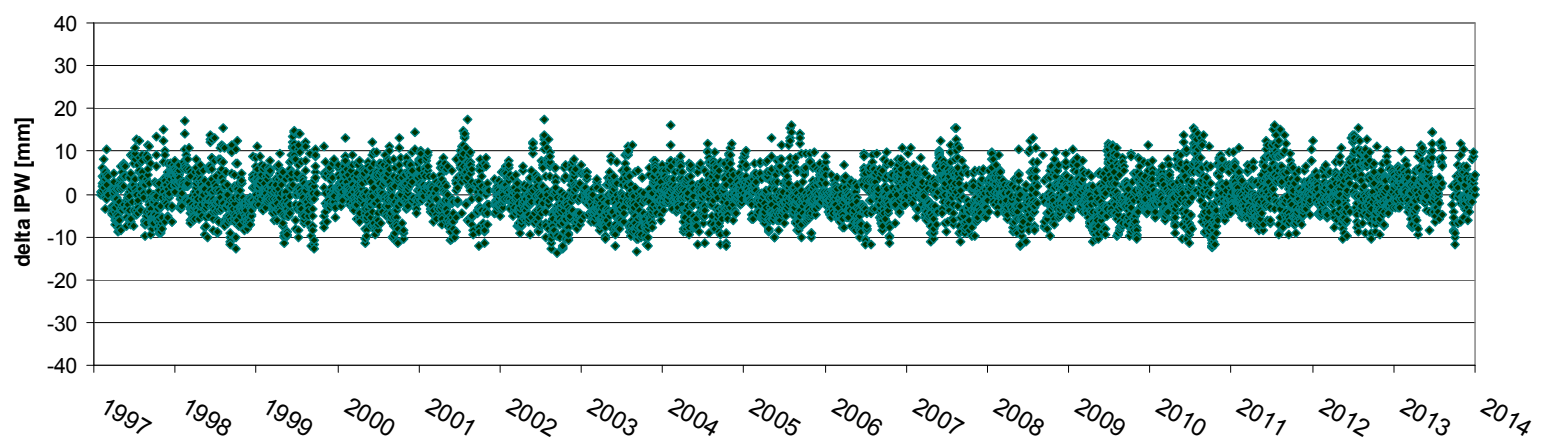

Fig. 11. IPW residuals for JOZE (IPW - simple annual oscillation model); 1997-2013 period

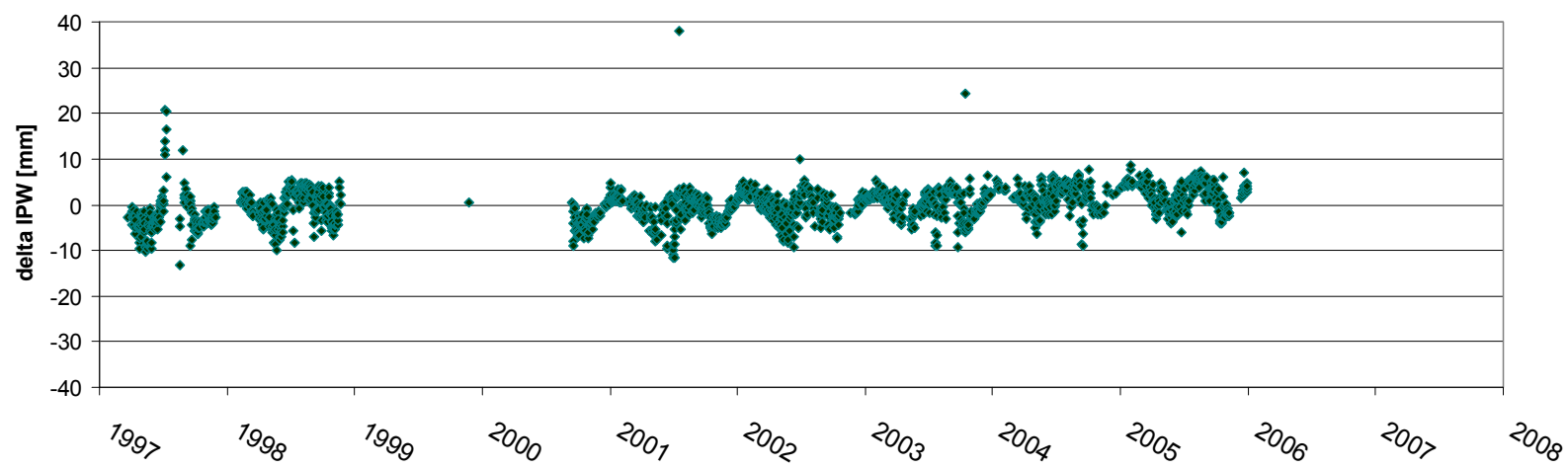

Fig. 12. IPW residuals for LHAS (Lhasa, Tibet); 1997-2005 period

Rarely trend itself is visible in residuals as in the case of LHAS (Lhasa) for years 1997-2005. Also some periodicity still remained in the residuals.

The second method is to fit more complicated model: annual sinusoid, semiannual sinusoid and linear trend at once in least square approach (this will be called ver. 2). 


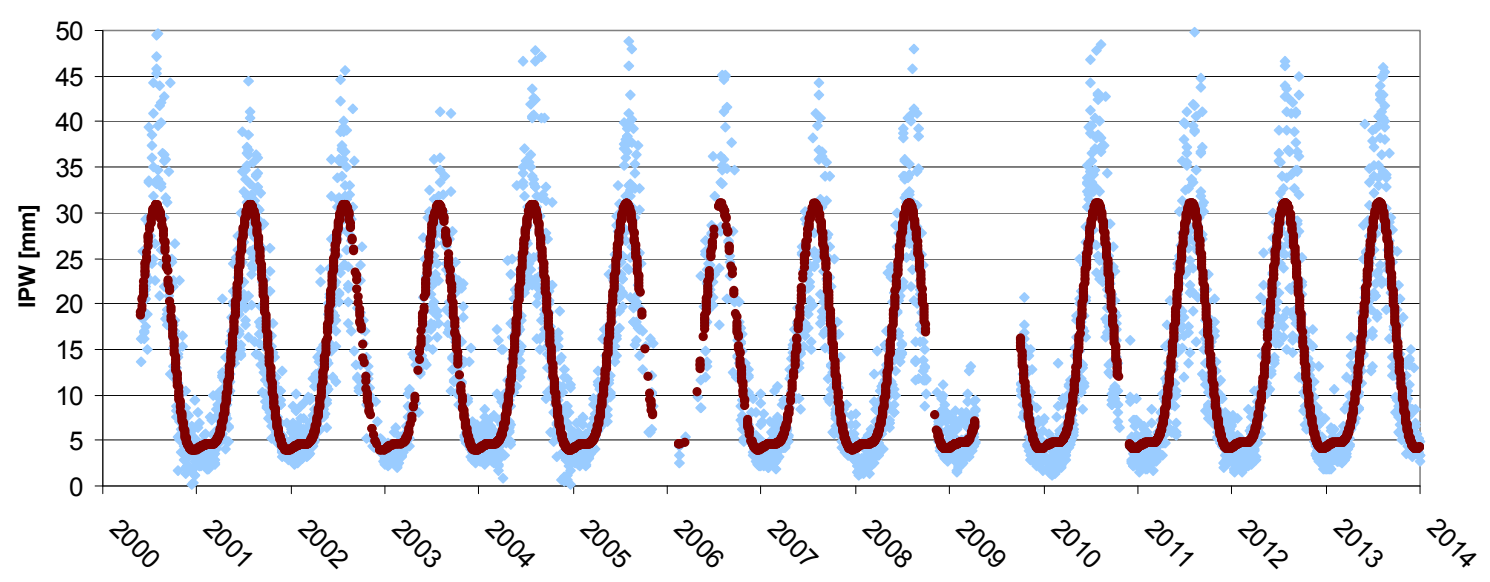

Fig. 13. IPW for YSSK (Yushno-Sakhalinsk, Russia) and model with 2 oscillations (annual and semiannual) applied to $2000-2013$ period

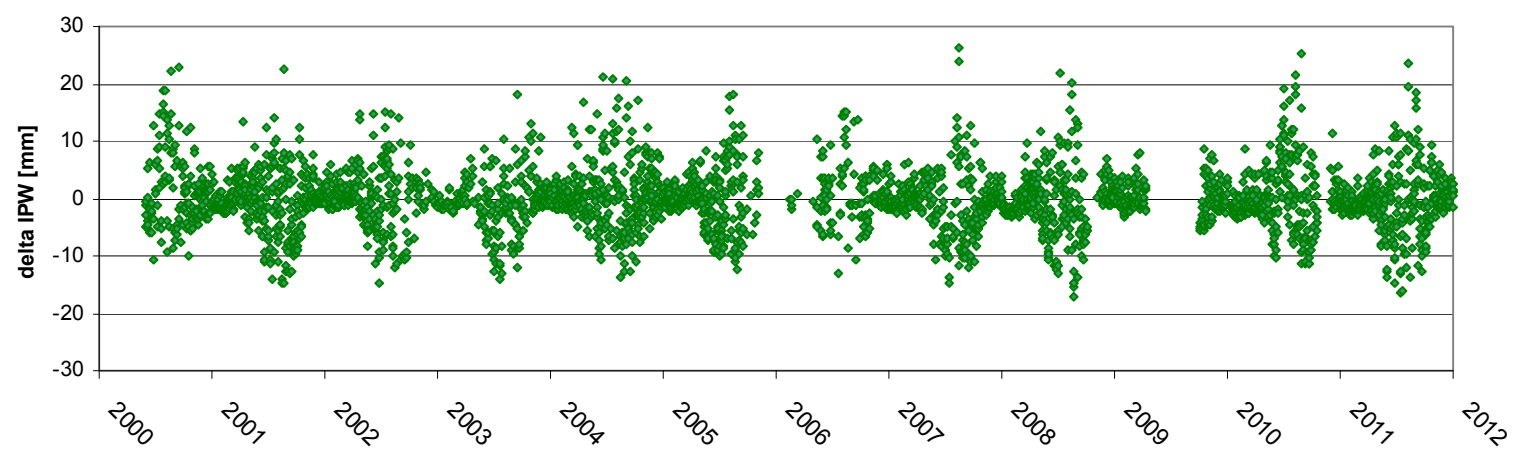

Fig. 14. IPW residuals (model with 2 oscillations) for YSSK, 2000-2013 period

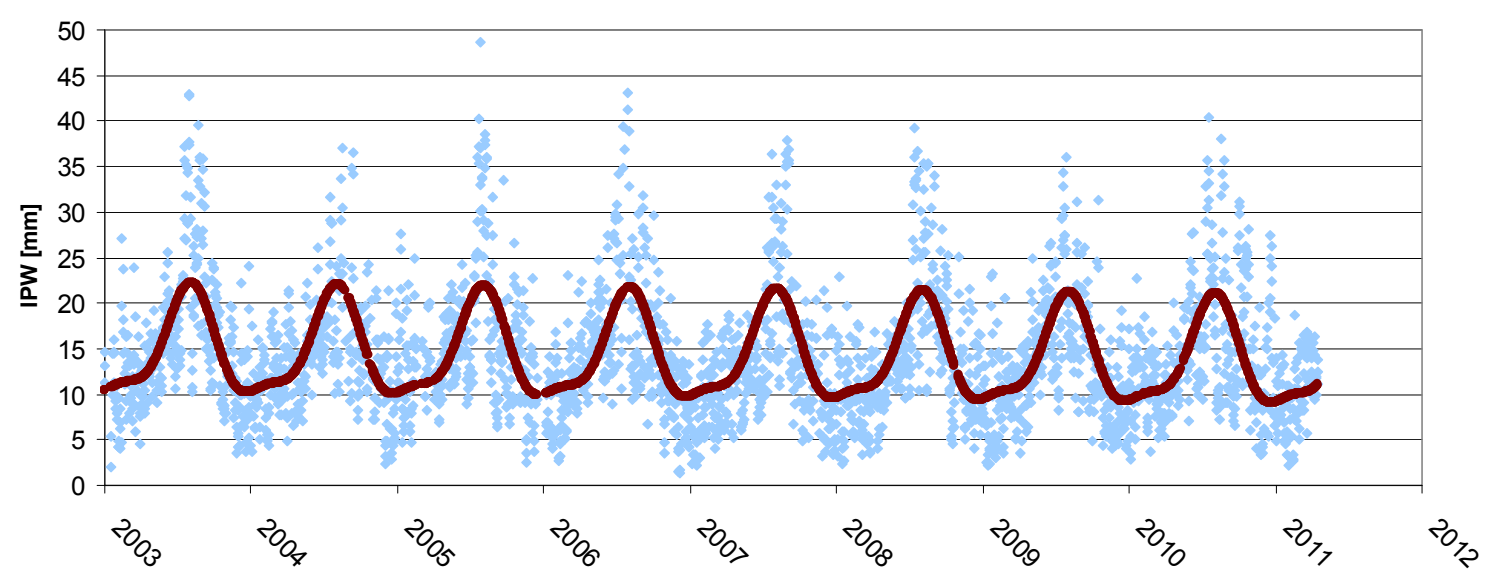

Fig. 15. IPW for CLAR (Claremont, California) and model with 2 oscillations (annual and semiannual) applied to 2003-2011 period 


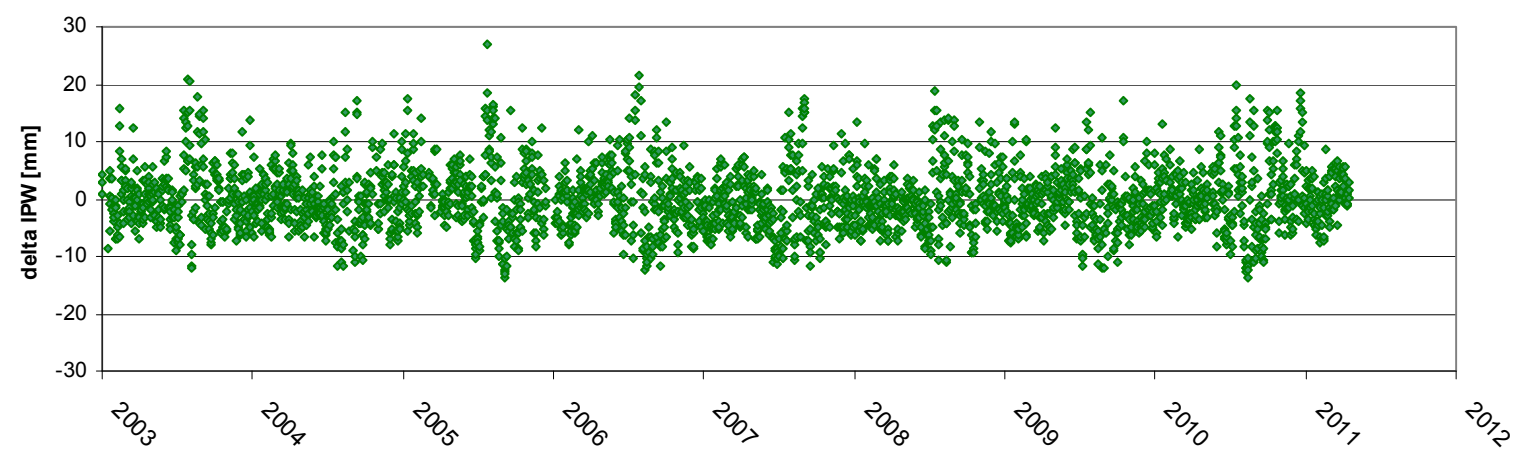

Fig. 16. IPW residuals (model model with 2 oscillations) for CLAR, 2003-2011 period

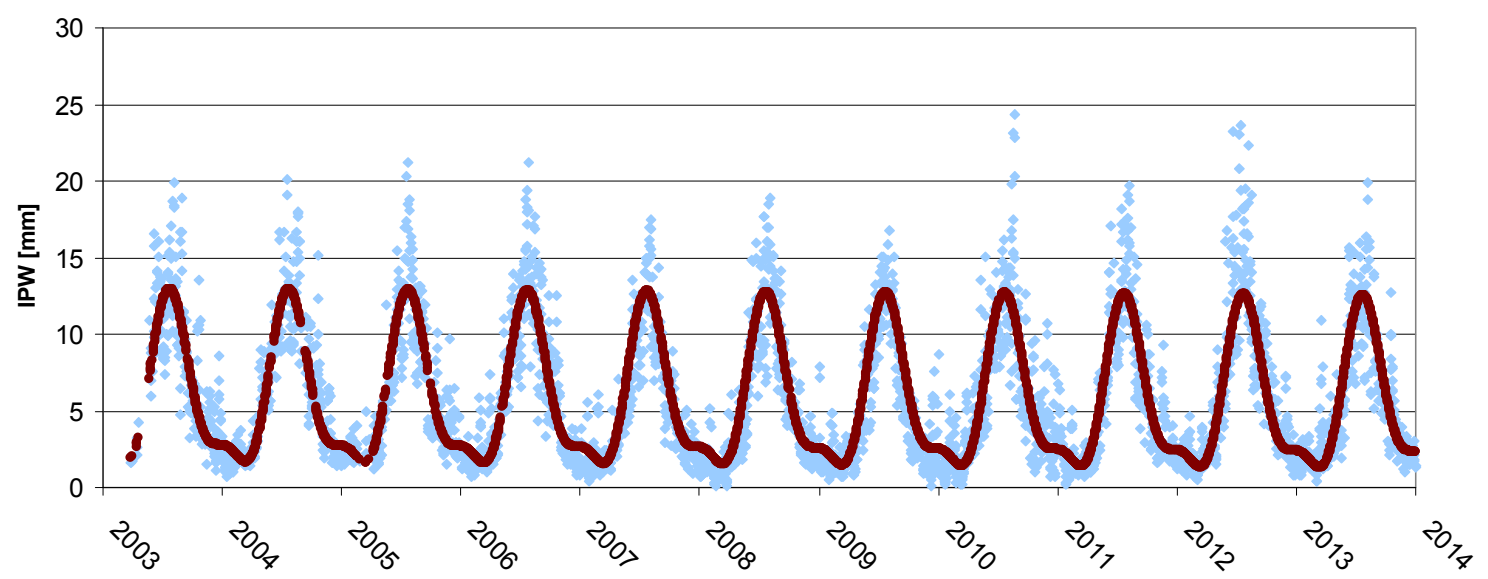

Fig. 17. IPW for THU2 (Thule, Greenland) and model with 2 oscillations (annual and semiannual) applied to 2003-2013 period

Two oscillation seasonal model can be easily developed by adding further periods, for instance still smaller fractions of the year.

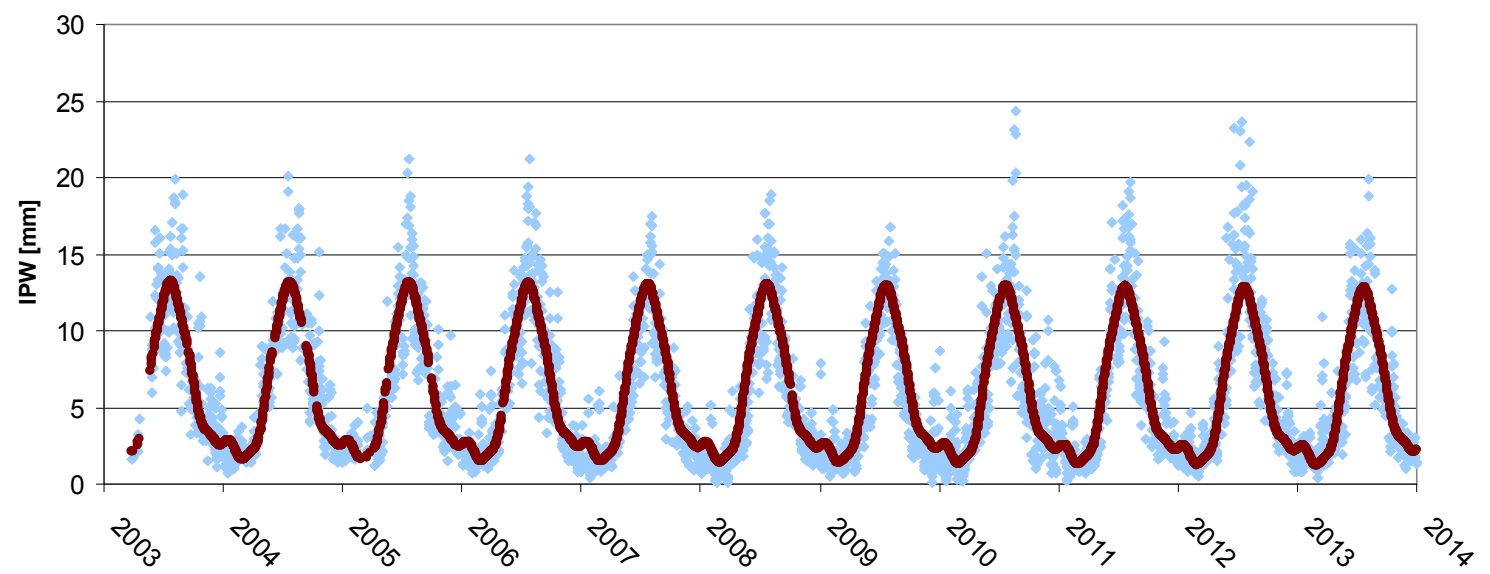

Fig. 18. IPW for THU2 (Thule, Greenland) and model with 3 oscillations (annual and 1/2, 1/3 -year) applied to 2003-2013 period 


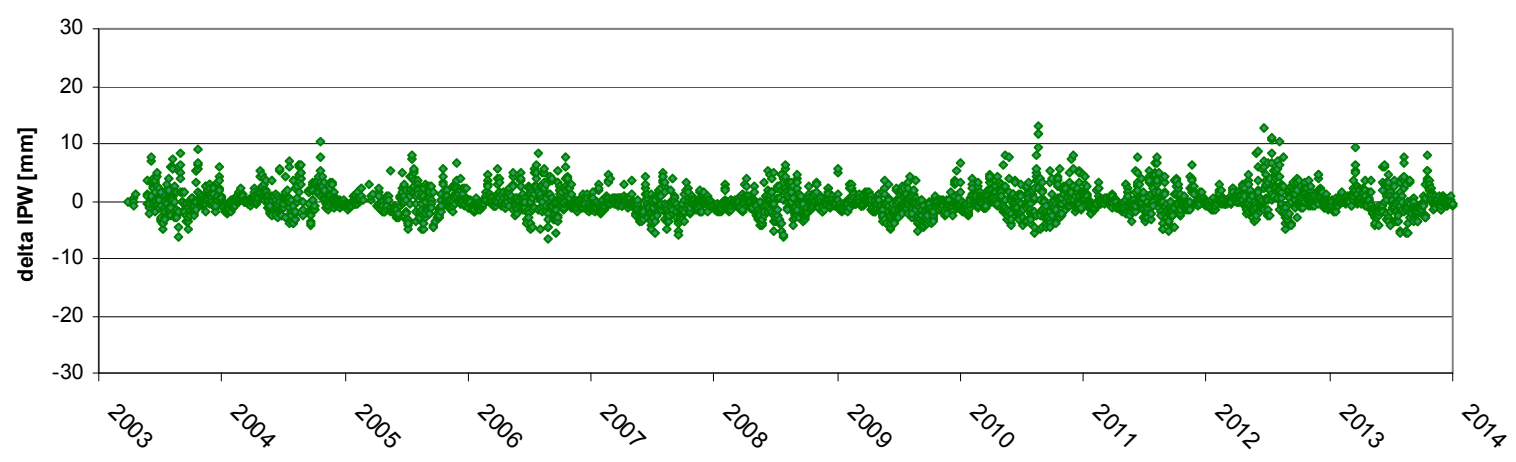

Fig. 19. IPW residuals (model with 4 oscillations) for THU2, 2003-2013 period

Some influence on final value of IPW can be the effect of IPW series incompleteness (GNSS station or meteorological device outage), e. g. observe the gap in the winter 2003/2004 for PDEL.

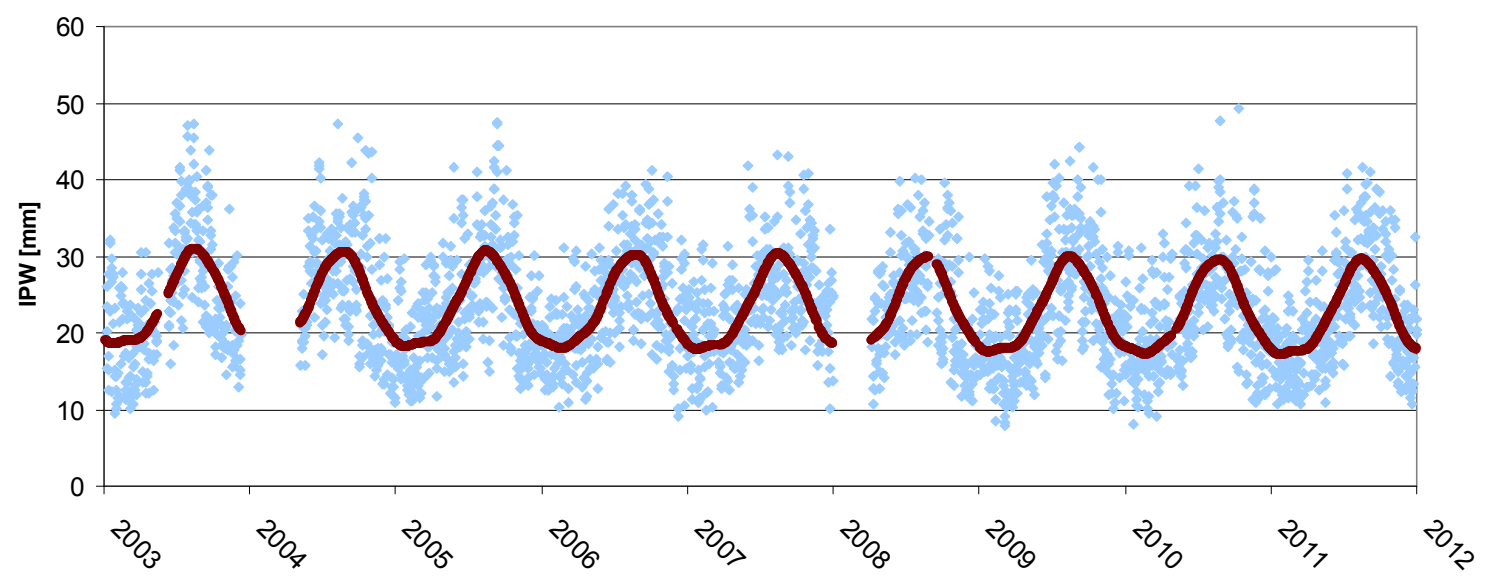

Fig. 20. IPW for PDEL (Azores) and model with 3 oscillations (annual and 1/2, 1/3 -year) applied to 2003-2012 period

We should analyze more closely the IPW series characteristic periods of seasonal/periodic changes by creating periodogram i.e. fitting (by the least square method) sequence of oscillations changing period from 4 to 500 days and put together obtained amplitudes.

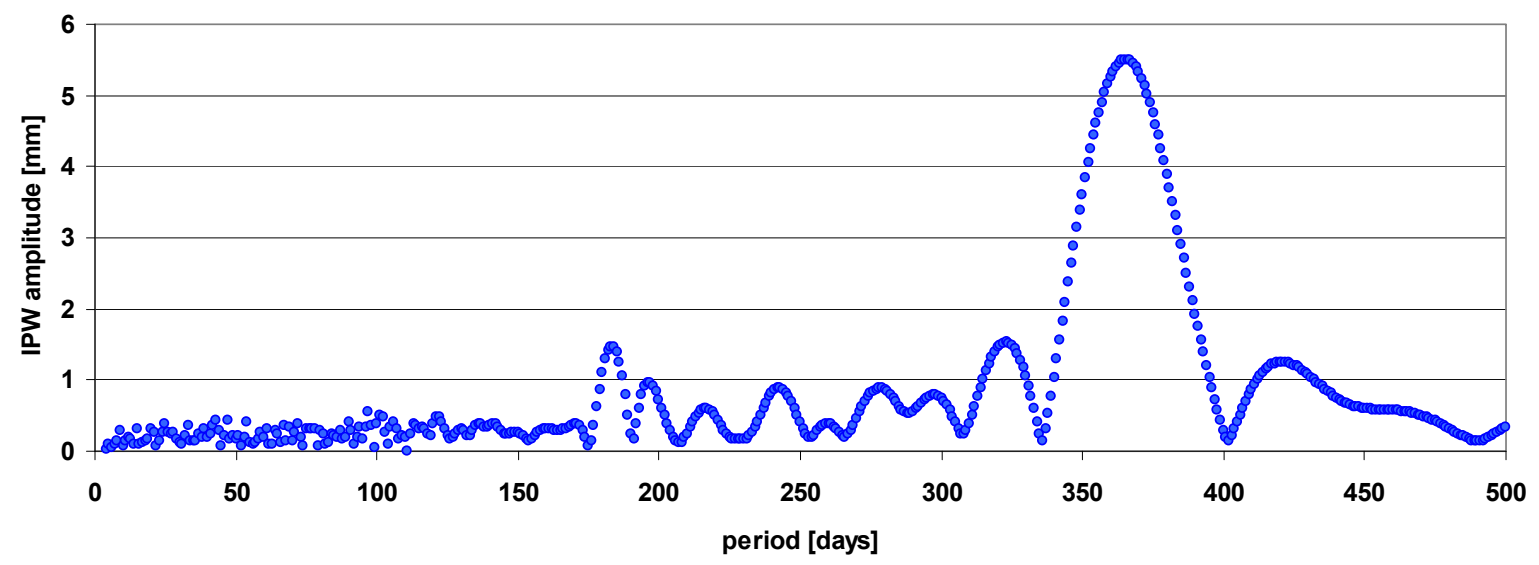

Fig. 21. Periodogram of IPW series for QAQ1 (Greenland) 


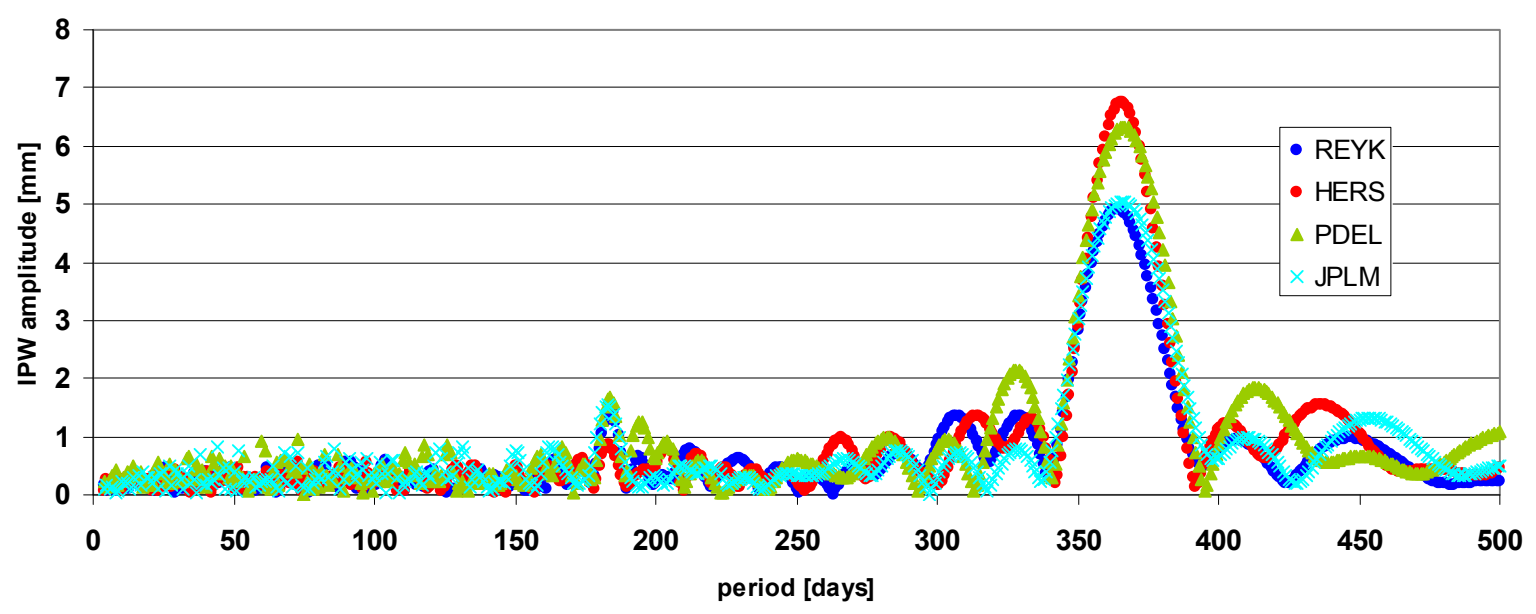

Fig. 22. Periodograms of IPW series for REYK, HERS, PDEL, JPLM

For some stations semiannual period is less conspicuous or not visible at all (like CHPI, see Fig.23).

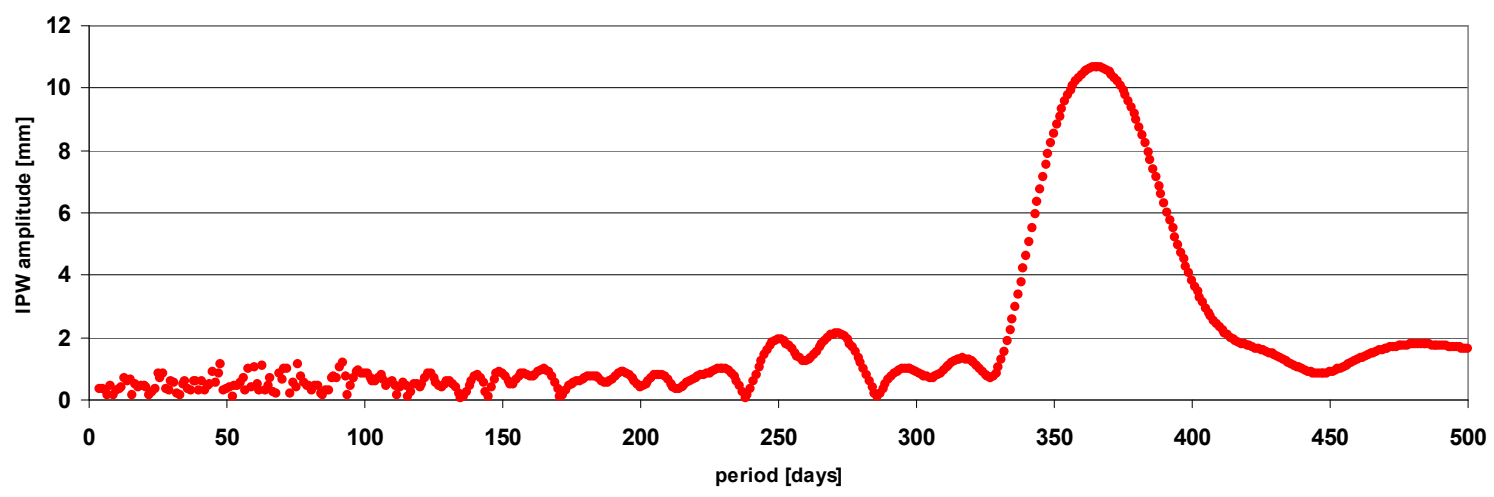

Fig. 23. Periodogram of IPW series for CHPI (Brazil)

Additionally we can quality of our model by creating of periodogram of residuals (e.g. JOZE series shown in the Fig. 24).

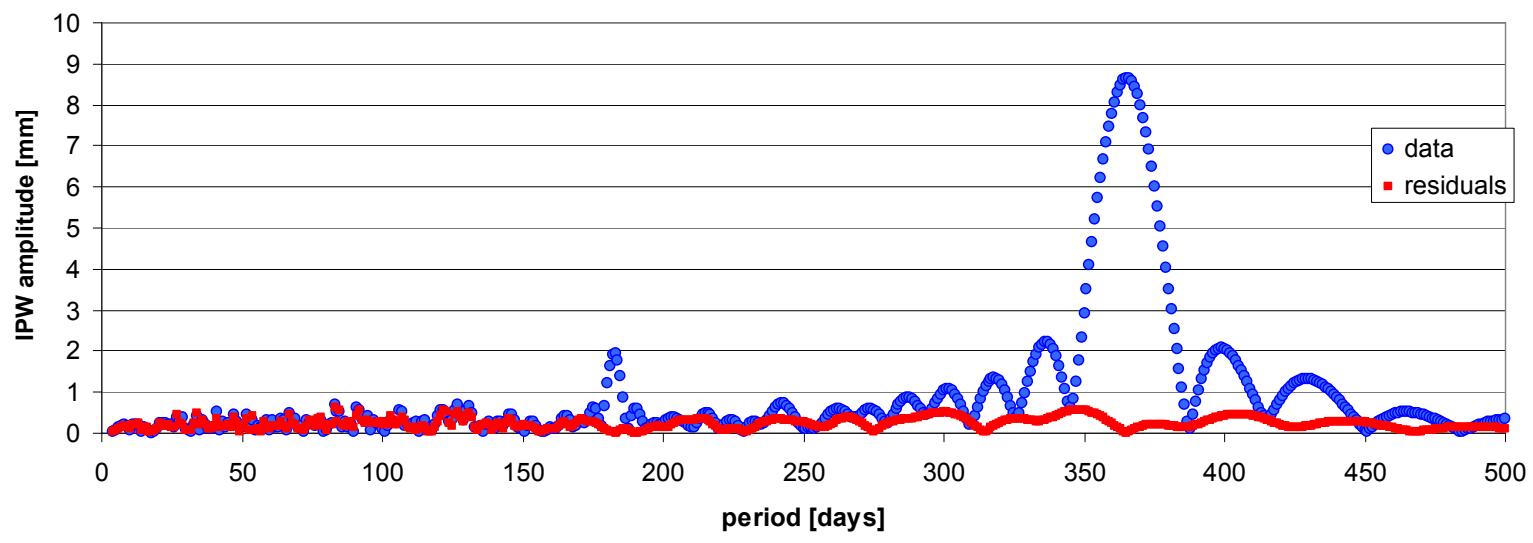

Fig. 24. Periodogram of IPW series and residuals after subtracting annual and semiannual oscillations for JOZE (Poland), 1997-2013 
The other periods beyond the annual and semiannual are week and inconsequential (in our stations set) but still we can try out various combinations empirically. Table 1 puts together linear trends and table 2 residuals obtained by fitting selected arbitrarily oscillation combinations for 4 stations.

Table 1. IPW linear trends obtained by fitting trend with selected oscillation combinations

\begin{tabular}{|l|c|c|c|c|}
\hline model & \multicolumn{4}{|c|}{ IPW trend [mm/y] } \\
\hline & JOZE & ZIMM & PDEL & THU2 \\
linear trend + & $1997-2013$ & $1997-2013$ & $2002-2013$ & $2003-2013$ \\
\hline $\mathrm{y}+\mathrm{y} / 2$ & 0.02751 & -0.04408 & -0.06597 & -0.05108 \\
\hline $\mathrm{y}+\mathrm{y} / 2+\mathrm{y} / 3$ & 0.02628 & -0.04372 & -0.06654 & -0.04803 \\
\hline $\mathrm{y}+\mathrm{y} / 2+\mathrm{y} / 4$ & 0.02807 & -0.04401 & -0.06512 & -0.05035 \\
\hline $\mathrm{y}+\mathrm{y} / 2+\mathrm{y} / 3+\mathrm{y} / 4$ & 0.02684 & -0.04366 & -0.06576 & -0.04729 \\
\hline $\mathrm{y}+\mathrm{y} / 2+\mathrm{y} / 4+\mathrm{y} / 8$ & 0.02815 & -0.04396 & -0.06519 & -0.05096 \\
\hline $\mathrm{y}+\mathrm{y} / 2+14 \mathrm{~d}+7 \mathrm{~d}$ & 0.02759 & -0.04415 & -0.06557 & -0.05102 \\
\hline $\mathrm{y}+\mathrm{y} / 2+\mathrm{y} / 4+\mathrm{y} / 8+\mathrm{y} / 16$ & 0.02803 & -0.04399 & -0.06679 & -0.05119 \\
\hline $\mathrm{y}+\mathrm{y} / 2+\mathrm{y} / 4+21 \mathrm{~d}+7 \mathrm{~d}$ & 0.02803 & -0.04414 & -0.06475 & -0.05038 \\
\hline $\mathrm{y}+\mathrm{y} / 2+\mathrm{y} / 4+\mathrm{y} / 8+\mathrm{y} / 16+\mathrm{y} / 32$ & 0.02800 & -0.04389 & -0.06627 & -0.05127 \\
\hline $\mathrm{y}+\mathrm{y} / 2+\mathrm{y} / 4+\mathrm{y} / 8+\mathrm{y} / 16+\mathrm{y} / 32+\mathrm{y} / 64$ & 0.02802 & -0.04387 & -0.06621 & -0.05126 \\
\hline
\end{tabular}

Table 2. IPW residuals after subtracting model of linear trend with selected oscillation combinations

\begin{tabular}{|l|c|c|c|c|}
\hline model & \multicolumn{4}{|c|}{ residuals RMS [mm] } \\
\hline linear trend + & $\begin{array}{c}\text { JOZE } \\
1997-2013\end{array}$ & $\begin{array}{c}\text { ZIMM } \\
1997-2013\end{array}$ & $\begin{array}{c}\text { PDEL } \\
2002-2013\end{array}$ & THU2 \\
$2003-2013$ \\
\hline $\mathrm{y}+\mathrm{y} / 2$ & 4.9281 & 3.8910 & 8.5994 & 2.1269 \\
\hline $\mathrm{y}+\mathrm{y} / 2+\mathrm{y} / 3$ & 4.9545 & 3.8907 & 8.6069 & 2.1659 \\
\hline $\mathrm{y}+\mathrm{y} / 2+\mathrm{y} / 4$ & 4.9309 & 3.8949 & 8.6011 & 2.1340 \\
\hline $\mathrm{y}+\mathrm{y} / 2+\mathrm{y} / 3+\mathrm{y} / 4$ & 4.9579 & 3.8946 & 8.6102 & 2.1725 \\
\hline $\mathrm{y}+\mathrm{y} / 2+\mathrm{y} / 4+\mathrm{y} / 8$ & 4.9305 & 3.8990 & 8.5996 & 2.1340 \\
\hline $\mathrm{y}+\mathrm{y} / 2+14 \mathrm{~d}+7 \mathrm{~d}$ & 4.9308 & 3.8924 & 8.6059 & 2.1281 \\
\hline $\mathrm{y}+\mathrm{y} / 2+\mathrm{y} / 4+\mathrm{y} / 8+\mathrm{y} / 16$ & 4.9329 & 3.9019 & 8.6102 & 2.1409 \\
\hline $\mathrm{y}+\mathrm{y} / 2+\mathrm{y} / 4+21 \mathrm{~d}+7 \mathrm{~d}$ & 4.9359 & 3.8959 & 8.5974 & 2.1360 \\
\hline $\mathrm{y}+\mathrm{y} / 2+\mathrm{y} / 4+\mathrm{y} / 8+\mathrm{y} / 16+\mathrm{y} / 32$ & 4.9351 & 3.9097 & 8.6107 & 2.1406 \\
\hline $\mathrm{y}+\mathrm{y} / 2+\mathrm{y} / 4+\mathrm{y} / 8+\mathrm{y} / 16+\mathrm{y} / 32+\mathrm{y} / 64$ & 4.9354 & 3.9109 & 8.6103 & 2.1414 \\
\hline
\end{tabular}

For most stations the simplest model (2 oscillations) provide us with smallest residuals. The following table 3 lists this model details further.

Table 3. IPW model of linear trend with 2 oscillations - least squares adjustment results for 4 stations

\begin{tabular}{|l|c|c|c|c|}
\hline fitted model parameters & JOZE & ZIMM & PDEL & THU2 \\
& $1997-2013$ & $1997-2013$ & $2002-2013$ & $2003-2013$ \\
\hline constant & 14.8 & 13.8 & 23.4 & 6.0 \\
\hline trend & 0.0275 & -0.0441 & -0.0660 & -0.0510 \\
\hline annual amplitude [mm] & 8.65 & 7.28 & 6.26 & 5.19 \\
\hline annual phase $\left[{ }^{\circ}\right]$ & -154 & -155 & -134 & -153 \\
\hline semiannual amplitude $[\mathrm{mm}]$ & 1.92 & 0.77 & 1.35 & 1.83 \\
\hline semiannual phase $\left[^{\circ}\right]$ & 26 & 53 & 93 & 38 \\
\hline
\end{tabular}


Summary of results obtained by fitting this "optimal" model are shown on table 5 but first some "auxiliary" results (still simpler version.1 and shorter series) are presented on table 4.

Table 4. Parameters of seasonal model adjusted to selected IPW series:

ver1: annual sinusoid (plus constant mean value) and linear trend shown by the residuals; ver2: annual and semiannual sinusoids plus linear trend fitted together (LS method).

\begin{tabular}{|l|l|l|c|c|c|l|c|}
\hline station & method & years & $\begin{array}{c}\text { annual } \\
\text { amplitude } \\
{[\mathrm{mm}]}\end{array}$ & $\begin{array}{c}\text { IPW mean } \\
{[\mathrm{mm}]}\end{array}$ & $\begin{array}{c}\text { residuals } \\
\mathrm{RMS} \\
{[\mathrm{mm}]}\end{array}$ & region & $\begin{array}{c}\text { IPW trend } \\
\text { [mm/y] }\end{array}$ \\
\hline JOZE & ver.1 & $1997-2011$ & 8.6 & 15.3 & 5.1 & Poland & -0.04 \\
\hline JOZE & ver.2 & $1997-2011$ & 8.6 & 15.6 & 4.9 & & -0.04 \\
\hline JOZE & ver.1 & $1997-2013$ & 8.7 & 15.1 & 5.1 & & 0.26 \\
\hline JOZE (E) & ver.1 & $2002-2010$ & 8.8 & 15.8 & 5.1 & & -0.11 \\
\hline STJO & ver.1 & $1998-2009$ & 8.6 & 15.0 & 6.7 & Newfoundland & -0.01 \\
\hline STJO & ver.2 & $1998-2009$ & 8.6 & 15.4 & 6.5 & & -0.01 \\
\hline REYK & ver.1 & $1997-2011$ & 5.0 & 12.2 & 4.1 & Iceland & 0.07 \\
\hline REYK & ver.2 & $1997-2011$ & 5.1 & 10.6 & 4.0 & & 0.13 \\
\hline THU2 & ver.1 & $2003-2011$ & 5.2 & 6.0 & 2.5 & Greenland & -0.13 \\
\hline THU2 & ver.2 & $2003-2011$ & 5.2 & 6.5 & 2.1 & & -0.11 \\
\hline CHUR & ver.1 & $2000-2010$ & 8.4 & 9.6 & 5.1 & north Manitoba & -0.12 \\
\hline CHUR & ver.2 & $2000-2010$ & 8.4 & 10.3 & 4.8 & & -0.13 \\
\hline DRAO & ver.1 & $2000-2010$ & 5.4 & 12.0 & 3.8 & British Columbia & -0.16 \\
\hline DRAO & ver.2 & $2000-2010$ & 5.4 & 12.8 & 3.7 & & -0.17 \\
\hline ZIMM & ver.1 & $1997-2011$ & 7.2 & 13.3 & 3.9 & Switzerland & -0.05 \\
\hline ZIMM & ver.2 & $1997-2011$ & 7.2 & 13.6 & 3.9 & & -0.04 \\
\hline ZIMM (E) & ver.2 & $2002-2011$ & 7.4 & 14.3 & 3.9 & & -0.18 \\
\hline USNO & ver.1 & $1997-2008$ & 13.1 & 21.4 & 8.7 & Washington DC & 0.02 \\
\hline USNO & ver.2 & $1997-2008$ & 13.2 & 21.4 & 8.5 & & 0.02 \\
\hline MDO1 & ver.1 & $1997-2010$ & 8.1 & 11.2 & 4.5 & Texas & 0.04 \\
\hline MDO1 & ver.2 & $1997-2010$ & 8.2 & 11.1 & 4.1 & & 0.02 \\
\hline JPLM & ver.1 & $2000-2011$ & 4.9 & 14.4 & 5.6 & California & -0.16 \\
\hline JPLM & ver.2 & $2000-2011$ & 4.9 & 15.3 & 5.5 & & -0.15 \\
\hline OHI2 & ver.1 & $2002-2011$ & 2.3 & 6.5 & 2.7 & Antarctica & -0.17 \\
\hline OHI2 & ver.2 & $2002-2011$ & 2.3 & 7.4 & 2.6 & & -0.17 \\
\hline E) IPW based & EPN & & & \\
\hline
\end{tabular}

(E) - IPW based on EPN tropospheric combination

For only 7 out of 33 stations this procedure have got positive IPW trend. Question if is it real phenomena or artefact caused by data processing details will finally be solved only by series lengthening, further tropospheric product improvement and including other IPW data sources of comparable time-span length. Also for extremely close pair THU2-THU3 with almost the same series length and the same span there is considerably different trend. Finally we can show final results graphically setting IPW trend values vs. station latitude (Fig. 25). Station KIT3 - evidently errorneous trend has been dropped out. 
Table 5. Parameters of linear plus seasonal model (annual and semiannual oscillation) adjusted to selected IPW series from IGS tropospheric product

\begin{tabular}{|c|c|c|c|c|c|c|}
\hline Station & years & $\begin{array}{l}\text { days in } \\
\text { series }\end{array}$ & region & $\begin{array}{l}\text { latitude } \\
\text { [deg.] }\end{array}$ & $\begin{array}{l}\text { station height } \\
\text { (ASL) [m] }\end{array}$ & $\begin{array}{l}\text { IPW trend } \\
{[\mathrm{mm} / \mathrm{y}]}\end{array}$ \\
\hline JOZE & 1997-2014 & 6086 & Poland & 52.086 & 109.3 & 0.054 \\
\hline LAMA & $2002-2014$ & 3897 & Poland & 53.892 & 157.7 & -0.008 \\
\hline WROC & $2002-2014$ & 3484 & Poland & 51.113 & 140.7 & 0.054 \\
\hline GOPE & $2002-2014$ & 4078 & Czech Republic & 49.914 & 546.8 & -0.120 \\
\hline ZIMM & $1997-2014$ & 5960 & Switzerland & 46.877 & 907.2 & -0.029 \\
\hline WTZR & $1997-2014$ & 5103 & Germany & 49.144 & 619.1 & -0.022 \\
\hline POTS & 1997-2011 & 4360 & Germany & 52.380 & 133.7 & -0.073 \\
\hline PTBB & $2003-2014$ & 4003 & Germany & 52.296 & 86.9 & -0.045 \\
\hline HERS & $1999-2014$ & 5071 & England & 50.867 & 31.0 & -0.036 \\
\hline MATE & 1999-2014 & 4838 & Italy & 40.649 & 489.4 & -0.117 \\
\hline$\overline{I S T A}$ & $2003-2014$ & 3659 & Turkey & 41.104 & 109.8 & -0.081 \\
\hline ANKR & $2002-2014$ & 3577 & Turkey & 39.888 & 937.1 & 0.059 \\
\hline PDEL & $2002-2014$ & 4435 & Azores & 37.748 & 54.0 & -0.061 \\
\hline REYK & 2001-2014 & 4473 & Iceland & 64.139 & 26.6 & 0.005 \\
\hline HOFN & $2002-2014$ & 3878 & Iceland & 64.267 & 17.3 & -0.049 \\
\hline QAQ1 & $2003-2014$ & 3967 & Greenland & 60.715 & 72.8 & -0.106 \\
\hline THU2 & $2003-2014$ & 4067 & Greenland & 76.537 & 19.3 & -0.043 \\
\hline THU3 & $2003-2014$ & 4152 & Greenland & 76.537 & 19.3 & -0.071 \\
\hline YSSK & $2000-2014$ & 4323 & Sakhalin, Russia & 47.030 & 65.8 & 0.009 \\
\hline KIT3 & $2004-2013$ & 2712 & Uzbekistan & 39.140 & 679.7 & -1.193 \\
\hline WUHN & $2002-2014$ & 3001 & China & 30.532 & 39.4 & -0.102 \\
\hline LHAS & $1997-2014$ & 4373 & Tibet & 29.657 & 3656.7 & 0.307 \\
\hline CHUR & $2000-2010$ & 3159 & Manitoba & 58.759 & 30.3 & -0.127 \\
\hline STJO & $2000-2009$ & 2857 & Newfoundland & 47.595 & 142.2 & -0.069 \\
\hline NRC1 & $2000-2011$ & 3454 & Ontario, Canada & 45.454 & 115.5 & -0.089 \\
\hline PRDS & $2000-2009$ & 2865 & Alberta, Canada & 50.871 & 1262.7 & -0.114 \\
\hline JPLM & $2000-2012$ & 4158 & California & 34.205 & 457.8 & -0.129 \\
\hline HOLP & $2002-2011$ & 3146 & California & 33.920 & 29.2 & -0.076 \\
\hline CLAR & $2002-2011$ & 2969 & California & 34.110 & 406.0 & -0.164 \\
\hline USNO & $1997-2008$ & 3466 & Washington DC & 38.919 & 81.1 & 0.029 \\
\hline $\mathrm{CHPI}$ & $2003-2014$ & 3033 & Brazil & -22.687 & 629.9 & -0.114 \\
\hline THTI & 2001-2014 & 4437 & Polynesia & -17.577 & 91.7 & -0.135 \\
\hline $\mathrm{OHI} 2$ & $2002-2014$ & 3476 & Antarctica & -63.321 & 18.3 & -0.166 \\
\hline
\end{tabular}

\section{latitude [deg.]}

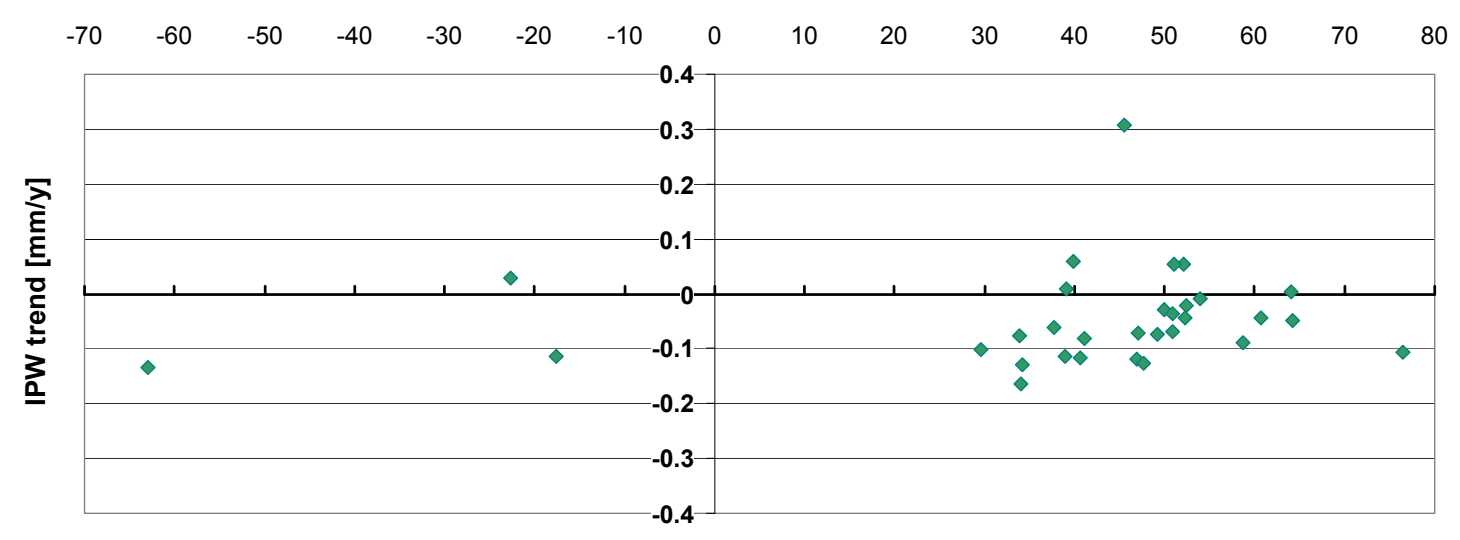

Fig. 25. IPW trend values [mm/y] in the function of IGS station latitude [deg.] 


\section{Conclusions}

IPW can serve as climatologic parameter. The shape of IPW annual series is relatively unique for different climates. Seasonal IPW changes should be eliminated or accounted in data treatment of IPW series. In this work simple model of annual and semiannual oscillation is used (there are no other recognizable periods as testifies both periodograms and attempts to fit more oscillations).

Details of model used to fit linear trend to IPW long series does not influence results (IPW trend) seriously. Much more influence is discernible when we change series length (add or drop some years at the beginning or the end of the series). Also solution minutes seems of less concern to obtain IPW trend.

Long series of IPW can be useful for climatology but many problems remain. For most IGS stations the author obtained negative IPW trend. Is it real phenomena or only cumulated effects of data itself (e.g. local meteo measurements problems) and data processing imperfections is as now hard to resolve. Periodic device malfunctions resulting in improbable measurement results are quite common - these have been removed from data set analyzed above - but possible tiny biases were not taken into consideration.

IPW trend depends on series length - both in terms of years used and series completeness. Unfortunately there are too little homogenous tropospheric solutions spanning many years. IGS tropospheric product has been subject to 2 fundamental changes in the period used.

\section{Acknowledgements}

This research was financially supported by the grant No. N N526 074038 of the Polish Ministry of Science and Higher Education/ National Science Centre. The author acknowledges the work of IGS staff, especially IGS tropospheric product developers: Gerd Gend, Yoaz Bar-Sever, Sung Byun and Sharyl Byram and EPN tropospheric product providers: Wolfgang Söhne and Rosa Pacione.

\section{References}

Andrews, D. G. (2010). An Introduction to Atmospheric Physics. Second Edition, Cambridge University Press

Bałdysz, Z., Nykiel, G., Figurski, M., Szafranek, K., Kroszczyński, K. (2015). Investigation of the 16-year and 18-year ZTD Time Series Derived from GPS Data Processing, Acta Geophysica 63(4), pp 1103-1125, doi: 10.1515/acgeo-2015-0033

Bevis, M., Businger, S., Herring, T., Rocken, C., Anthes, R., \& Ware, R. (1992). GPS Meteorology: Remote Sensing of Atmospheric Water Vapour using the Global Positioning System, J. Geophys. Res., 97, pp 15,787-15,801

Byun, S. H., Bar-Sever, Yoaz E. (2009). A new type of troposphere zenith path delay product of the international GNSS service. J. Geod. 83 (2009): pp 367-373, doi: $10.1007 / \mathrm{s} 00190-008-0288-8$ 
Davis, J. L., Herring, T. A., Shapiro, I. I., Rogers, A. E., \& Elgered, G. (1985). Geodesy by radio interferometry: Effects of atmospheric modeling errors on estimates of baseline length, Radio Sci., 20, pp 1593-1607. doi:10.1029/RS020i006p01593

Duan, J., Bevis, M., Fang, P., Bock, Y., Chiswell, S., Businger, S., Rocken, C., Solheim, F., Van Hove, T., Ware, R., McClusky, S., Herring, T. A. \& King, R. W. (1996). GPS meteorology: direct estimation of the absolute value of precipitable water. J. Applied Met. 35, 830-838. doi:10.1175/1520-0450

Forster, P., Ramaswamy V., Artaxo P., Berntsen T., Betts R., Fahey D.W., Haywood J., Lean J., Lowe D.C., Myhre G., Nganga J., Prinn R., Raga G., Schulz M. and Van Dorland R. (2007). Changes in Atmospheric Constituents and in Radiative Forcing. In: Climate Change 2007: The Physical Science Basis. Contribution of Working Group I to the Fourth Assessment Report of the Intergovernmental Panel on Climate Change [Solomon, S., D. Qin, M. Manning, Z. Chen, M. Marquis, K.B. Averyt, M.Tignor and H.L. Miller (eds.)]. Cambridge University Press, Cambridge, United Kingdom and New York

Gradinarsky, L.P., Johansson, J.M., Bouma, H.R, Scherneck, H.-G., Elgered, G. (2002). Climate monitoring using GPS. Physics and Chemistry of the Earth, 27 pp.335-340. doi: 10.1016/S1474-7065(02)00009-8

Hofmann-Wellenhof, B., Lichtenegger, H., Wasle, E. (2008). GNSS - Global Navigation Satellite Systems GPS, GLONASS, Galileo, and more. Springer Wien NewYork

Jin, S., Park, J.-U., Cho, J.-H., Park, P.-H. (2007). Seasonal variability of GPSderived zenith tropospheric delay (1994-2006) and climate implications. J.Geophys. Res., 112: D09110. doi:10.1029/2006JD007772

Kruczyk, M. (2014). Integrated Precipitable Water from GNSS as a climate parameter, Geoinformation Issues Vol. 6, No 1 (6), 21-35/2014

Kruczyk, M., Liwosz, T., (2012). Tropospheric Delay from EPN Reprocessing by WUT LAC as Valuable Data Source - in Comparison to Operational EPN Products and Aerological Data, Reports on Geodesy, No 1 (92) /2012, pp. 105-118

Mcllven, R. (2010). Fundamentals of Weather and Climate, Second Edition, Oxford University Pess

Ning, T., Elgered, G. (2012). Trends in the atmospheric water vapour content from ground-based GPS: The impact of the elevation cutoff angle. IEEE Journal of Selected Topics in Applied Earth Observations and Remote Sensing, 5 pp. 744751. doi:10.1109/JSTARS.2012.2191392

Rocken, C., Ware, R., Van Hove, T., Solheim, F., Alber, C., Johnson, J., Bevis, M., Businger, S. (1993). Sensing atmospheric water vapor with the Global Positioning System. Geophys. Res. Lett., 20, 2631 
Salby, M. L. (2012). Physics of the Atmosphere and Climate. Cambridge University Press

Shelton, M. L. (2009). Hydrometeorology. Perspectives and Applications. Cambridge University Press

Trenberth, K. E., Dai, A., Rasmussen, R.M. and Parsons, D.B. (2003). The changing character of precipitation. Bull. Amer. Meteor. Soc., 84 (9), pp. 1205-1217. doi: 10.1175/BAMS-84-9-1205

Yuan, L.L., Anthes. R.A., Ware, R.H., Rocken, C., Bonner, W.D., Bevis, M.G., Businger, S. (1993). Sensing Climate Change Using the Global Positioning System. J.Geophys. Res., Vol. 98 No. D8, pp. 14925 - 14937

Authors:

Michał Kruczyk ${ }^{1)}, \underline{\text { kruczyk@gik.pw.edu.pl }}$

1) Department of Geodesy and Geodetic Astronomy

Faculty of Geodesy and Cartography

Warsaw University of Technology

PI. Politechniki 1, 00-661, Warsaw, Poland 